\title{
AVALIAÇÃO NUTRICIONAL DE ALGUNS ALIMENTOS PARA EQÜINOS POR MEIO DE ENSAIOS METABÓLICOS ${ }^{1}$
}

\author{
Nutritional evaluation of some equine's feedstuffs by metabolic Assays \\ Cristiano Alves Moretini², José Augusto de Freitas Lima ${ }^{3}$, \\ Elias Tadeu Fialho ${ }^{3}$, Juliane Rezende Mercer ${ }^{4}$, Roberta Ariboni Brandi ${ }^{5}$
}

\begin{abstract}
RESUMO
O presente trabalho foi conduzido no Departamento de Zootecnia da Universidade Federal de Lavras - MG, com o objetivo de determinar o valor nutricional de alguns alimentos para eqüinos. Os alimentos foram avaliados por meio de seis ensaios metabólicos em um delineamento inteiramente casualizado, sendo a unidade experimental representada pelo cavalo mantido individualmente em gaiolas de metabolismo. Um total de seis ingredientes: soja integral tostada, semente de linhaça, feno de rama de mandioca, feno de rama de cenoura e feno de tifton. Para a determinação dos coeficientes de digestibilidade aparente dos alimentos (CDA), foi utilizado o método da Coleta Total de Fezes. Os resultados obtidos na base da matéria seca para soja integral tostada foram: $32 \%$ de proteína digestível (PD) e $3.732 \mathrm{kcal} / \mathrm{kg}$ de energia metabolizável (EM); milho floculado: 7,7\% de PD e $3.325 \mathrm{kcal} / \mathrm{kg}$ de EM; semente de linhaça: 16,5\% de PD e $3.724 \mathrm{kcal} / \mathrm{kg}$ de EM; feno de rama de mandioca: 3,3\% de PD e $874 \mathrm{kcal} / \mathrm{kg}$; feno de rama de cenoura: 7,9\% de PD e $1.405 \mathrm{kcal} / \mathrm{kg}$ de EM e feno de tifton: 7,1\% de PD e 1.427 $\mathrm{kcal} / \mathrm{kg}$ de EM. Com esses resultados, evidencia-se que entre os alimentos concentrados a soja integral tostada foi o único alimento que propiciou simultaneamente um alto nível protéico e energético. A semente de linhaça e o milho floculado apresentaram elevado valores de EM, embora ambos tenham sido muito semelhantes ao da soja integral tostada. Para os alimentos volumosos, ficou evidenciado por meio dos resultados que o maior PD foi obtido pelo feno da rama de cenoura, cujo resultado foi similar ao obtido pelo o feno de tifton. Os resultados de composição química e valores nutricionais dos alimentos estudados podem contribuir para uma formulação adequada de rações para eqüinos.
\end{abstract}

Termos para indexação: Eqüinos, digestibilidade, ingredientes.

\section{ABSTRACT}

The present study was carried out at the Animal Science Department at Universidade Federal de Lavras - MG, in order to determine the nutritional value of some equine feedstuffs. Each feed was evaluated by using a metabolism assay, six horses in six replications each one represented as experimental unit.. Three feed concentrates were tested: full-fat toasted soybean, steam-flaked corn and flaxseed, as well as, 3 hays: cassava stem leaf, carrot stem leaf and Tifton. A total faeces collection method was used to determine for each feed nutritional values by using the apparent digestibility coefficients (ADC). Results based on dry matter obtained for full-fat toasted soybean were: $32 \%$ of digestible protein (DP) and $3.732 \mathrm{kcal} / \mathrm{kg}$ of metabolizable energy (ME); steam-flaked corn: 7,7\% DP and $3.325 \mathrm{kcal} / \mathrm{kg} \mathrm{ME}$; flaxseed: $16,5 \%$ DP and $3.724 \mathrm{kcal} / \mathrm{kg} \mathrm{ME}$; cassava stem leaf hay: 3,3\% DP and $874 \mathrm{kcal} / \mathrm{kg} \mathrm{ME}$; carrot stem leaf hay: 7,89\% DP and $1.405 \mathrm{kcal} / \mathrm{kg}$ ME, and finally, Tifton hay: 7,1\% DP and $1.427 \mathrm{kcal} / \mathrm{kg}$ ME. These results indicate that among the concentrates tested, the full-fat toasted soybean should supply sufficiently both protein and energy intake. Even with similarly high EM levels of full-fat toasted soybean, detected for both flaxseed and steam-flaked corn, they were respectively $48 \%$ and $76 \%$. The hay results shown highest content in DP was verified in carrot stem leaf hay, which was close to that of tifton. In conclusion based on the chemistry analyses and nutritional values results observed on this experiment for the tested feeds should contribute on adequate equines ration formulation.

Index terms: Equines, full-fat toasted soybean, steam-flaked corn, flaxseed, cassava stem leaf hay, carrot stem leaf hay, tifton hay and feed apparent digestibility coefficient.

(Recebido para publicação em 7 de fevereiro de 2003 e aprovado em 3 de novembro de 2003)

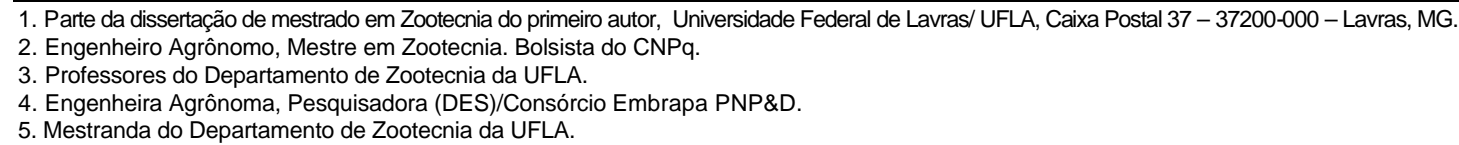




\section{INTRODUÇÃO}

O eqüino está destinado a papéis muito variáveis. Do cavalo de corrida, exige-se velocidade; do cavalo de esporte, a força, bem como uma certa rusticidade; do reprodutor, espera-se boa fecundidade; do cavalo destinado ao matadouro, busca-se um rápido desenvolvimento. Em quase todas as raças, a tendência atual é de produzir animais mais fortes, mais precoces e mais versáteis. Seja qual for a anatomia e finalidade, o cavalo tem como qualquer outro ser vivo necessidade de encontrar em sua alimentação os nutrientes necessários ao seu crescimento, manutenção e trabalho. Para ser completo, no entanto, o alimento deve conter não apenas os nutrientes básicos necessários, como também esses devem estar em perfeito equilíbrio.

Entretanto, poucos estudos a respeito da nutrição eqüina são verificados na literatura científica, sendo ainda menor esse número quando relacionado às condições específicas do País. Por conseqüência à escassez de informação, muitas das formulações técnicas que vêm sendo realizadas para os rebanhos nacionais utilizam tabelas estrangeiras para recomendações de nutrientes por analogia a outros animais domésticos, como por exemplo, as do National Research Council. No entanto, a tecnologia brasileira existente é suficiente para o desenvolvimento de programas nutricionais sérios, racionais e sensivelmente mais econômicos do que a utilizada pela alimentação clássica.

Outro enfoque de grande importância reside nas implicações resultantes da baixa produtividade de grãos dos países em desenvolvimento, acentuando o problema de competitividade por alimentos entre o homem e os animais domésticos. Existem em nossos campos de produção toneladas de alimentos de alta qualidade, que poderiam estar sendo aproveitados para a alimentação de eqüinos, em vez de servirem meramente como adubo orgânico. Ênfase deve ser dada às pesquisas destinadas ao estudo do aproveitamento de alimentos nãoconvencionais à alimentação humana, representando a oportunidade de alimentar de forma mais econômica e racional os eqüinos.

Com base nessas constatações, com a presente pesquisa buscou-se determinar o valor nutricional de alguns alimentos que possam efetivamente contribuir para a formulação técnica de rações específicas para equiinos adaptadas às condições nacionais. Entre os materiais testados, optou-se estrategicamente por avaliar alguns alimentos mais conhecidos, como: soja integral tostada, milho floculado (ambos comumente utilizados na sua forma integral) e feno de tifton, e também, alguns alimentos alternativos, como: semente de linhaça, feno de rama de cenoura e feno de rama de mandioca, totalizando três alimentos concentrados e três volumosos.

\section{MATERIAL E MÉTODOS}

O experimento foi conduzido na sala de metabolismo de eqüinos do Departamento de Zootecnia da Universidade Federal de Lavras, durante o ano de 2001, sendo as coletas realizadas durante os meses de junho a novembro do mesmo ano. Foram utilizados cavalos machos, castrados, sem raça definida, com idade aproximada de 10 anos e com peso médio de $317 \pm 22,45$ $\mathrm{Kg}$. Foram avaliados três alimentos volumosos: feno de folha de mandioca, feno de rama de cenoura e feno de tifton e três alimentos concentrados: milho floculado, soja integral tostada e semente de linhaça. Os dados de digestibilidade foram analisados de acordo com um delineamento inteiramente casualizado (DIC), sendo os tratamentos constituídos dos 6 ingredientes estudados. Um total de seis ensaios foram conduzidos, e em cada ensaio avaliou-se um ingrediente utilizando-se 8 cavalos (repetição), sendo a unidade experimental representada pelo animal mantido em uma gaiola metabólica.

O período pré-experimental teve duração de 10 dias, com o objetivo de adaptar os animais à gaiola de metabolismo e à dieta. A gaiola metabólica utilizada seguiu o modelo adaptado às condições do País, proposto por Furtado e Tosi (1996). O período de coleta foi fixado em cinco dias, segundo recomendação de Vander Noot et al. (1967). O experimento foi dividido em 6 períodos de 15 dias, sendo testado um alimento por período, para a determinação da digestibilidade.

Durante os períodos de avaliação dos concentrados, os cavalos receberam feno de capim tifton moído como alimento básico, sendo substituído pelos alimentos-teste em diferentes proporções, conforme adaptação dos animais, aumentando-se os teores de substituição até que os animais reduzissem o consumo ou até os limites recomendados na literatura. O nível de substituição do feno de tifton pelos alimentos-teste, na base da matéria seca, foi de respectivamente, $15 \%, 15 \%$ e $5 \%$, para a soja integral tostada, milho floculado e semente de linhaça. As fezes foram pesadas diariamente e homogeneizadas, retirando-se, em seguida, uma amostra representativa de $10 \%$. A urina foi coletada diariamente, medindo-se o peso e, após homogeneização, foi retirada uma amostra de $200 \mathrm{ml}$. Nos coletores de urina, foram adicionados, todos os dias, $60 \mathrm{ml} \mathrm{de} \mathrm{HCl}$ a $50 \%$,

Ciênc. agrotec., Lavras, v. 28, n. 3, p. 621-626, maio/jun., 2004 
para evitar a volatilização do nitrogênio. O material coletado, exceto a urina, após secagem forçada, foi moído e preparado para análise de proteína bruta $(\mathrm{PB})$, energia bruta (EB), matéria seca (MS), matéria mineral (MN), de acordo com Silva (1981); fibra em detergente neutro (FDN) e fibra em detergente ácido (FDA), de acordo com Goering e Soest, citado por Silva (1981). As amostras de urina foram resfriadas a $100^{\circ} \mathrm{C}$, até o final de período de coleta, quando, então, seguiram para a análise de proteína bruta (PB) e energia bruta (EB). O coeficiente de digestibilidade da MS e dos nutrientes dos fenos foram calculados de acordo com as equações propostas por Ott et al. (1979). O coeficiente de digestibilidade dos nutrientes dos alimentos-teste foram calculados por diferença, utilizando-se a fórmula de Matterson et al. (1965).

\section{RESULTADOS E DISCUSSÃO}

\section{Composição Bromatológica dos Alimentos Testados}

A composição bromatológica dos alimentos testados está apresentada na Tabela 1. Observa-se que a composição bromatologicas dos fenos testados é semelhante à composição citada no NRC (1989) para feno de Coast cross, com exceção do elevado teor protéico do feno de rama de cenoura, e o feno de Tifton apresentou elevado teor de FDN, o que pode ser atribuído ao período de coleta desse. Todos os fenos estudados apresen- tam levado teor de FDA, o que pode ser atribuído, no caso do feno de Tifton, ao processamento tardio do material, e para o feno de rama de mandioca, a presença de levada proporção caule folha, aumentando, assim, o teor fibra do material. $\mathrm{O}$ feno da parte aérea da cenoura apresenta valores mais próximos ao feno de alfafa, citados no NRC (1989), porém notam-se também elevados teores de FDN e FDA no material. O milho floculado foi o alimento que forneceu o resultado mais elevado para porcentagem de MO, e o mais reduzido para porcentagem de cinzas, embora tais valores tenham sido similares aos obtidos no experimento de Watson (1987) para o endosperma do milho.A composição bromatológica da linhaça-grão é semelhante à citada no NRC (1989).O valor nutricional da soja integral tostada é superior ao encontrado no NRC, fato que pode ser explicado pelo processamento do material.

\section{Consumo de Nutrientes}

\section{Coeficiente de Digestibilidade Aparente dos Nutrientes}

Na tabela 3 estão apresentados os valores de coeficiente de digestibilidade aparente da matéria seca, matéria orgânica, proteína bruta, fibra em detergente ácido, fibra em detergente neutro e energia bruta dos alimentos testados.

TABELA 1 - Composição Bromatológica dos alimentos².

\begin{tabular}{|c|c|c|c|c|c|c|}
\hline \multirow{3}{*}{$\begin{array}{c}\text { Nutrien- } \\
\text { te }^{1}\end{array}$} & \multicolumn{6}{|c|}{ Percentagem $(\%)$ na base da matéria seca } \\
\hline & \multicolumn{3}{|c|}{ Feno } & \multicolumn{3}{|c|}{ Concentrado } \\
\hline & $\begin{array}{c}\text { Rama } \\
\text { Mandioca }\end{array}$ & $\begin{array}{c}\text { Rama } \\
\text { Cenoura }\end{array}$ & Tifton & $\begin{array}{c}\text { Soja Integral } \\
\text { tostada }\end{array}$ & $\begin{array}{c}\text { Milho } \\
\text { Floculado }\end{array}$ & $\begin{array}{l}\text { Semente } \\
\text { Linhaça }\end{array}$ \\
\hline MS & 92,19 & 89,95 & 92,32 & 95,02 & 89,9 & 96,21 \\
\hline PB & 7,81 & 15,39 & 10,19 & 36,71 & 9,23 & 22,44 \\
\hline FDN & 68,07 & 66,97 & 88,72 & 47,83 & 13,54 & 87,40 \\
\hline FDA & 58,16 & 51,34 & 49,64 & 36,34 & 13,99 & 66,14 \\
\hline MO & 87,84 & 74,66 & 93,57 & 96,53 & 99,72 & 97,38 \\
\hline Cinzas & 12,17 & 25,35 & 6,43 & 3,47 & 0,275 & 2,62 \\
\hline
\end{tabular}

1 /Dados obtidos de duas repetições.

2/Valores obtidos por meio de análises realizadas no Laboratório de Nutrição Animal / DZO - UFLA. 
O coeficiente de digestibilidade da MS do feno da parte aérea da mandioca foi de $28,67 \%$. Esse baixo valor foi atribuído à alta fração fibrosa (FDN $68,07 \%$ e FDA 58,16\%) contida no alimento. Os baixos coeficientes de digestibilidade da FDN $(14,81 \%)$ e da FDA $(11,77 \%)$, PB $(41,77 \%)$, matéria orgânica $(24,64 \%)$ foram atribuídos à formação de complexos entre a FDN, FDA, proteína e taninos, citados por Reed et al. (1982), que constatou que 26 a $58 \%$ da $\mathrm{PB}$ estão ligados à FDN, da mesma forma que 8 a $13 \%$ estão ligados à FDA; além de a PB estar relacionada à formação de complexos com taninos, reduzindo a digestibilidade protéica. Da mesma forma, esse princípio poderia explicar os menores valores observados de digestibilidade de MO, FDA e FDN. A EB apresenta coeficiente de digestibilidade de $21,1 \%$.A baixa digestibilidade dos nutrientes da linhaça também pode ser explicada pela formação desse complexo, sendo coeficientes de digestibilidade da MS da linhaça-grão de 78,66\%, da FDN $(38,98 \%)$, da FDA $(37,75 \%)$ e da proteína $(73,5 \%)$. A baixa digestibilidade da matéria orgânica $(41,11 \%)$ pode ser atribuída à qualidade da fibra. A EB apresentou coeficiente de digestibilidade de $60,06 \%$, valor baixo que pode ser atribuído ao baixo aproveitamento do animal, pois a maior parte da energia está na forma de fibra, pobremente digerida, limitando a atuação dos microorganismos do ceco, como ocorrido com o feno da parte aérea da mandioca. A linhaça ainda apresenta em sua composição a lignana, que por se unir ao complexo formado, limita ainda mais a digestibilidade dos nutrientes do ingrediente.

O feno da parte aérea da cenoura apresenta coeficientes da digestibilidade da FDN $(68,19 \%)$ e da FDA $(59,74 \%)$ comparáveis aos coeficientes encontrados para polpa cítrica, apresentando coeficientes de digestibilidade de FDN $(57,71 \%)$ e FDA $(61,35 \%)$. É considerado baixo o coeficiente de digestibilidade da PB $(51,71 \%)$, quando comparado com o coeficiente de digestibilidade do feno de alfafa $(82,18 \%)$. Entretan- to, o coeficiente de digestibilidade da matéria orgânica $(57,71 \%)$ apresenta valores próximos ao do feno de alfafa $(56,24 \%)$ e do feno de Coast cross $(54,54 \%)$. Quanto ao coeficiente de digestibilidade da EB $(48,55 \%)$, esse valor está próximo ao encontrado para o feno de Tifton $(50,43 \%)$, Perali (2001).

Araújo et al. (2000), trabalhando farelo de soja para eqüinos, encontraram resultados inferiores aos obtidos, trabalhando com soja integral tostada, para a digestibilidade da matéria seca, que foi de $79,64 \%$ para o farelo de soja e de $84,1 \%$ para a soja integral tostada.A digestibilidade da energia foi superior para o farelo de soja $(85,06 \%)$. Para a digestibilidade de proteína, o citado autor encontrou digestibilidade de $153,07 \%$, enquanto a digestibilidade encontrada neste trabalho foi de $86,6 \%$, valor já considerado alto. De acordo com Bertol et al. (1994), a tostagem da soja integral influenciou positivamente a digestibilidade dos nutrientes: MS, ED, EM, MS e PB, e tais resultados conferem com os valores obtidos no presente experimento.

O feno de Tifton apresentou valores de digestibilidade semelhantes aos encontrados por Araújo et al. (2000), trabalhando com feno de Coast cross, sendo os valores da digestibilidade da MS de 40,9\% para o feno de Tifton e 43,47\% para o feno de Coast cross. A digestibilidade da proteína bruta foi de $69,3 \%$ e $40,41 \%$, respectivamente; tal diferença pode ser atribuída ao período de maturação do feno.Os coeficientes de digestibilidade da energia, FDA, FDN foram respectivamente para os fenos de: $40,9 \%$ e $42,87 \%, 40,4 \%$ e $34,4 \%, 44,4 \%$ e $45,69 \%$.

$\mathrm{O}$ milho floculado apresentou coeficientes de digestibilidade semelhante aos obtidos por Araújo et al. (2000), trabalhando com milho, sendo os coeficientes de MS, PB, FDN e EB para o milho floculado e para o milho de $83,7 \%$ e $89,43 \%, 83 \%$ e $83,06 \%, 59,5 \%$ e $53,92 \%, 89,2 \%$ e $81,15 \%$, respectivamente. A floculação do milho influenciou apenas na digestibilidade da energia. 
TABELA 3 - Coeficientes de digestibilidade aparente da matéria seca (CDAMS), matéria orgânica (CDAMO), proteína bruta (CDAPB), fibra em detergente ácido (CDAFDA), fibra em detergente neutro (CDAFDN) e energia bruta (CDAEB) dos alimentos-teste por meio do método de coleta total.

\begin{tabular}{lcccccc}
\hline \multirow{2}{*}{ Alimentos } & \multicolumn{6}{c}{ Coeficientes de Digestibilidade Aparente (\%) } \\
\cline { 2 - 7 } & CDAMS & CDAMO & CDAPB & CDAFDA & CDAFDN & CDAEB \\
\hline Feno de Rama de Mandioca & $28,7 \pm 5,8^{2}$ & $24,6 \pm 5,7$ & $41,8 \pm 5,8$ & $11,8 \pm 8,2$ & $14,8 \pm 5,7$ & $24,8 \pm 6,0$ \\
Feno de Rama de Cenoura & $52,2 \pm 4,5$ & $57,7 \pm 4,4$ & $51,3 \pm 4,8$ & $59,7 \pm 4,6$ & $68,2 \pm 4,9$ & $48,6 \pm 5,1$ \\
Feno de tifton & $40,9 \pm 0,4$ & $41,3 \pm 0,4$ & $69,3 \pm 1,0$ & $40,4 \pm 0,4$ & $44,4 \pm 0,3$ & $40,9 \pm 1,3$ \\
Soja Integra Tostada & $84,1 \pm 4,4$ & $82,4 \pm 6,8$ & $86,6 \pm 1,9$ & $46,5 \pm 5,8$ & $56,6 \pm 6,2$ & $72,9 \pm 1,8$ \\
Milho Floculado & $83,7 \pm 1,9$ & $90,2 \pm 6,2$ & $83,0 \pm 2,3$ & $54,9 \pm 4,7$ & $59,5 \pm 4,3$ & $89,2 \pm 2,3$ \\
Semente de Linhaça & $78,7 \pm 2,5$ & $76,4 \pm 4,5$ & $73,5 \pm 8,5$ & $47,6 \pm 5,0$ & $53,6 \pm 7,5$ & $60,9 \pm 1,8$ \\
\hline CV (\%) & 39,15 & 41,11 & 26,22 & 38,98 & 37,75 & 41,12 \\
\hline
\end{tabular}

$1 /$ Resultados obtidos a partir da média de 2 observações avaliadas.

2/Valor correspondente ao desvio padrão da média

\section{CONCLUSÕES}

O milho floculado e a soja grão tostada tiveram alto valor nutricional, ao passo que os fenos de mandioca e cenoura apresentaram valores nutricionais similares a outros fenos utilizados na alimentação de eqüinos.

Conclui-se que os dados de composição química e valores nutricionais dos alimentos estudados podem contribuir para uma formulação adequada de rações para eqüinos.

\section{AGRADECIMENTOS}

Em especial ao Conselho Nacional de Desenvolvimento Científico e Tecnológico - CNPq, pela concessão da bolsa de estudos.

\section{REFERÊNCIAS BIBLIOGRÁFICAS}

ARAÚJO, K. V.; LIMA, J. A. de F.; FIALHO, E. T.; MIYAGI, E. S. Comparação dos indicadores internos com o método de coleta total para determinar a digestibilidade dos nutrientes de dietas mistas em eqüinos. Ciências e Agrotecnologia, Lavras, v. 24, n. 4, p. 1041-1048, out./dez. 2000.

BERTOL, T. M.; LIMA, G. J. M. M.; ZANOTTO, D. L. Valores de composição química e de digestibilidade de alguns alimentos para suínos. Revista da Sociedade Brasileira de Zootecnia, Viçosa, v. 23, n. 6, p. 182184, 1994.

FURTADO, C. E.; TOSI, H. Gaiola de metabolismo para eqüinos. In: REUNIÃO ANUAL DA SOCIEDADE BRASILEIRA DE ZOOTECNIA, 33., 1996, Fortaleza. Anais... Fortaleza: SBZ, 1996. v. 4, p. 192-193.

MATTERSON, L. D.; POTTER, L. M.; STUTZ, M. $\mathrm{W}$. The metabolizable energy of feeds ingredient for chickens. Connecticut: The University of Connecticut, Agricultural Experiment Station, 1965. 11 p. (Research Report, 7).

NATIONAL RESEARCH COUNCIL. Nutrients requeriments of domestic animals. Washington: National Academy of Science, 1989. 64 p.

OTT, E. A.; FEASTER, J. B.; LIEB, S. Acceptability and digestibility of dried citrus pulp by horses. Journal of Animal Science, Champaign, v.49, n. 4, p. 983-987, Oct. 1979.

PERALI, C. Valores nutricionais de alimentos para eqüiinos. Ciência e Agrotecnologia, Lavras, v. 25, n. 5, p. 1216-1224, set./out. 2001. 
REED, J. D.; MCDOWELL, R. E.; SOEST, P. J. van; HORVATH, P. J. Condensed tannins: a factor limiting the use of cassava forage. Journal of the Science of Food and Agriculture, London, v. 33, n. 3, p. 213220, Mar. 1982.

SILVA, D. J. Análises de alimentos: métodos químicos e biológicos. 1981. 166 f. Tese (Doutorado em Ciências dos Alimentos) - Universidade Federal de Viçosa, Viçosa, 1981.
VANDER NOOT, G. W.; SYMONS, L. D.; LYDMAN, R. K. Rate of passage of various feedstuffs through the digestive trait of horses. Journal of Animal Science, Champaing, v. 26, n. 6, p. 13091311, Nov. 1967.

WATSON, S. A. Structure and composition. In: WATSON, S. A.; RAMSTAD, P. E. Corn: chemistry and technology. Saint Paul: American Association Cereal Chemistry, 1987. p. 53-82. 